Supplementary Material

\title{
DETERMINATION OF ANTIBODY-DRUG CONJUGATE RELEASED PAYLOAD SPECIES USING DIRECTED IN VITRO ASSAYS AND MASS SPECTROMETRIC INTERROGATION
}

Andrew J. Bessire, ${ }^{* \dagger}$ T. Eric Ballard, ${ }^{\dagger}$ Manoj Charati, ${ }^{\ddagger}$ Justin Cohen, ${ }^{\S}$ Michael Green, ${ }^{\#}$ MyHanh Lam, ${ }^{\ddagger}$ Frank Loganzo, ${ }^{\ddagger}$ Birte Nolting, ${ }^{\perp}$ Betsy Pierce, ${ }^{\|}$Sujiet Puthenveetil, ${ }^{\|}$Lee Roberts, ${ }^{\#}$ Klaas Schildknegt, ${ }^{\top}$ Chakrapani Subramanyam $\|^{\prime}$

${ }^{\dagger}$ Pharmacokinetics, Dynamics and Metabolism, "Worldwide Medicinal Chemistry, and 'Pharmaceutical Sciences Chemical R\&D, Pfizer Worldwide R\&D, Groton, CT 06340

‡Oncology Research Unit, and ${ }^{\perp}$ Bioprocess R\&D, Pfizer Worldwide R\&D, Pearl River, NY 10965

\#Worldwide Medicinal Chemistry, and ${ }^{\S}$ Global Biotherapeutics Technologies, Pfizer Worldwide R\&D, Cambridge, MA 02139

1. Chemical Synthesis

S2-S3

2. Supplemental Figures

S4-S8 


\section{General methods for chemical synthesis}

Starting materials and reagents were purchased from Aldrich or VWR and used as received. Analytical thin-layer chromatography (TLC) was performed on glass plates, precoated with silica gel. Flash chromatography was carried out using silica gel 60 (Redisep) as the stationary phase. Analytical HPLC was performed on reversed phase-HPLC (RP-HPLC) instruments, using C18 columns and a binary solvent system (MeCN and $\mathrm{H}_{2} \mathrm{O}$ with $0.1 \% \mathrm{CF}_{3} \mathrm{CO}_{2} \mathrm{H}$ ). ${ }^{1} \mathrm{H}$ NMR spectra were recorded on Varian $400 \mathrm{MHz}$ or Bruker $500 \mathrm{MHz}$ spectrometers. Chemical shifts are reported in ppm relative to the signals corresponding to the residual non-deuterated solvents $\left(\mathrm{CD}_{3} \mathrm{OD}: \delta 3.31 \mathrm{ppm}\right.$ and DMSO-d 6 : $\left.\delta 2.50 \mathrm{ppm} / 298 \mathrm{~K}\right)$.

\section{Synthesis of mc-Val-Cit-PABC-Spirocyclic Nicotinamide}

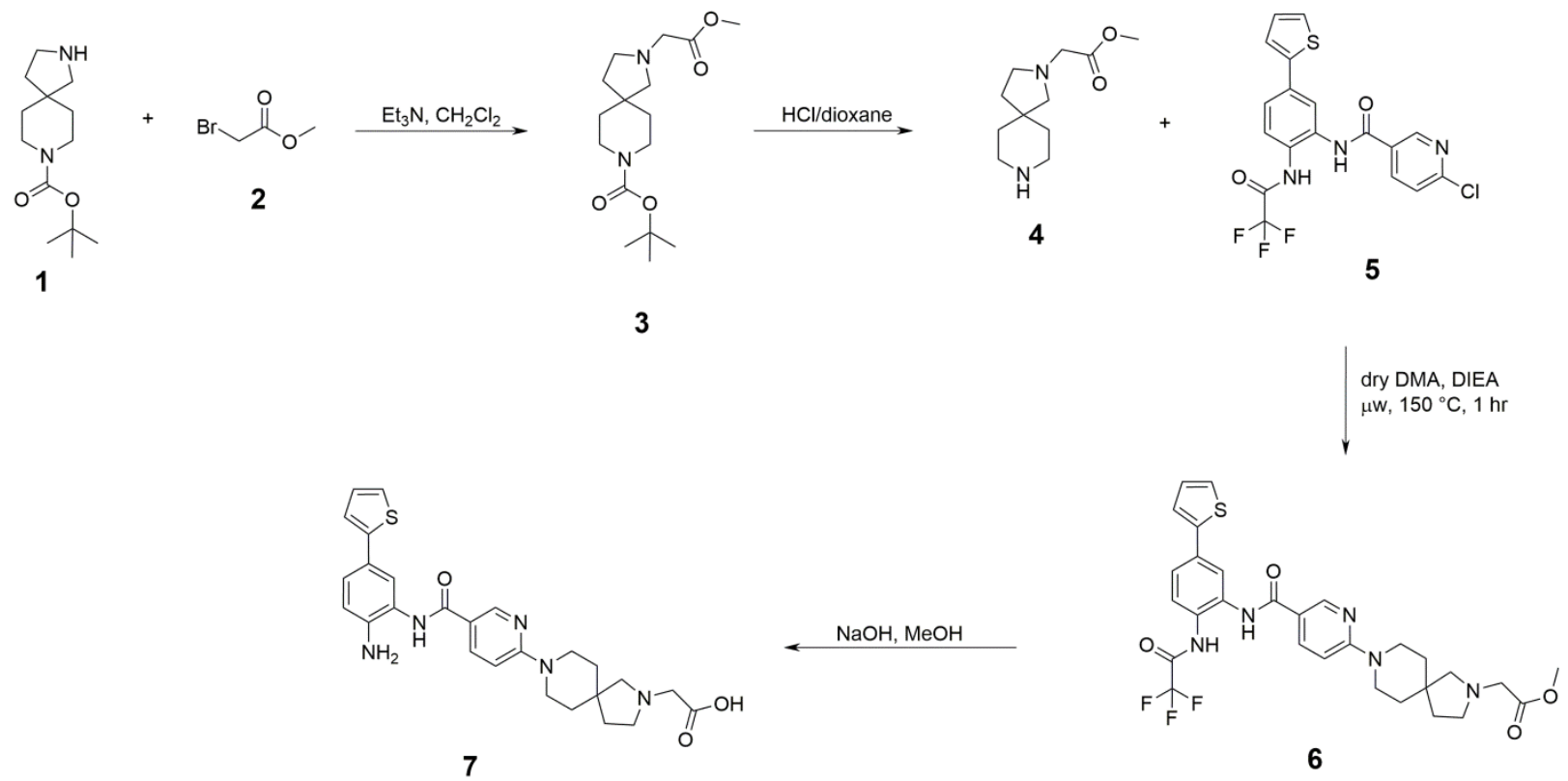

Spirocyclic Nicotinamide Intermediate 7: To a solution of compound 1 (5.0 g, $20.8 \mathrm{mmol})$ in $60 \mathrm{~mL}$ of dry DCM was added $\mathrm{Et}_{3} \mathrm{~N}$ (6.32 g, $\left.62.4 \mathrm{mmol}\right)$ and compound 2 (4.14 g, $27.0 \mathrm{mmol}$ ). The mixture was stirred at $10-20^{\circ} \mathrm{C}$ for $16 \mathrm{~h}$. The reaction mixture was added to water (200 $\mathrm{mL})$ and extracted with DCM (3 x $300 \mathrm{~mL})$. The organic layer was washed with water $(2 \times 150$ $\mathrm{mL}$ ), and concentrated to give crude product, which was purified by ISCO flash chromatography on silica gel (eluent: DCM:MeOH, from pure 100/0 to 10/1) to provide desired product compound 3 (5.2 g, $80 \%$ ) as a yellow oil [LRMS ESI $\mathrm{m} / \mathrm{z}(\mathrm{M}+\mathrm{H}: 313.2)$ ]. To a solution of compound 3 (5.2 g, $16.6 \mathrm{mmol}$ ) in $20 \mathrm{~mL}$ of dry dioxane was added $4 \mathrm{M} \mathrm{HCl} /$ dioxane $(20 \mathrm{~mL})$. The reaction mixture was stirred at $10-20^{\circ} \mathrm{C}$ for $4 \mathrm{~h}$. The reaction mixture was concentrated to give desired product compound 4 (4.80 g, 100\%) as a yellow solid [LRMS ESI $\mathrm{m} / \mathrm{z}(\mathrm{M}+\mathrm{H}$ : 213.1)]. To a solution of compound 5 (200.0 mg, $0.470 \mathrm{mmol})$ in $8 \mathrm{~mL}$ of DMF was added DIEA (364 mg, $2.82 \mathrm{mmol}$ ) and compound 4 (199 mg, $0.939 \mathrm{mmol}$ ) under $\mathrm{N}_{2}$. The reaction mixture was stirred and heated at $150{ }^{\circ} \mathrm{C}$ for $3 \mathrm{~h}$ in microwave. The reaction mixture was concentrated and the residue was added to water $(100 \mathrm{~mL})$ and extracted with DCM $(3 \times 200$ $\mathrm{mL})$. The organic layer was washed with water $(80 \mathrm{~mL})$, and concentrated to give crude product, 
which was purified by ISCO flash chromatography on silica gel (eluent: DCM:MeOH, from pure 100/0 to 10/1) to provide desired product compound 6 (280 mg, 79\%) as a yellow oil [LRMS ESI m/z (M+H: 601.9)]. Compound 6 (0.040 g, $0.066 \mathrm{mmol})$ was diluted with $\sim 5 \mathrm{~mL}$ of methanol in a vial, treated with $\sim 1 \mathrm{~mL}$ of $1 \mathrm{M} \mathrm{NaOH}$, capped, and stirred at $40{ }^{\circ} \mathrm{C}$ for $3 \mathrm{~h}$. The reaction solution was adsorbed onto silica gel and purified by normal phase chromatography on silica gel eluting with $0-100 \% \mathrm{MeOH}$ in DCM to afford compound 7 upon concentration as a tan solid (0.030 g, 94\%). LRMS ESI m/z (M+H: 492.0). ${ }^{1} \mathrm{H}$ NMR (400 MHz, CD 3 OD) $\delta 8.70-$ $8.84(\mathrm{~m}, 1 \mathrm{H}), 8.06-8.20(\mathrm{~m}, 1 \mathrm{H}), 7.78-7.87(\mathrm{~m}, 1 \mathrm{H}), 7.43-7.54(\mathrm{~m}, 1 \mathrm{H}), 7.33-7.41(\mathrm{~m}$, 1H), 7.22 (br. s., 2H), $6.98-7.06$ (m, 1H), 6.78 - 6.95 (m, 2H), 3.75 (br. s., $6 \mathrm{H}), 3.48$ - 3.61 (m, 2H), 3.40 (m, 2H), 2.09 (m, 2H), 1.79 (br. s., 4H).
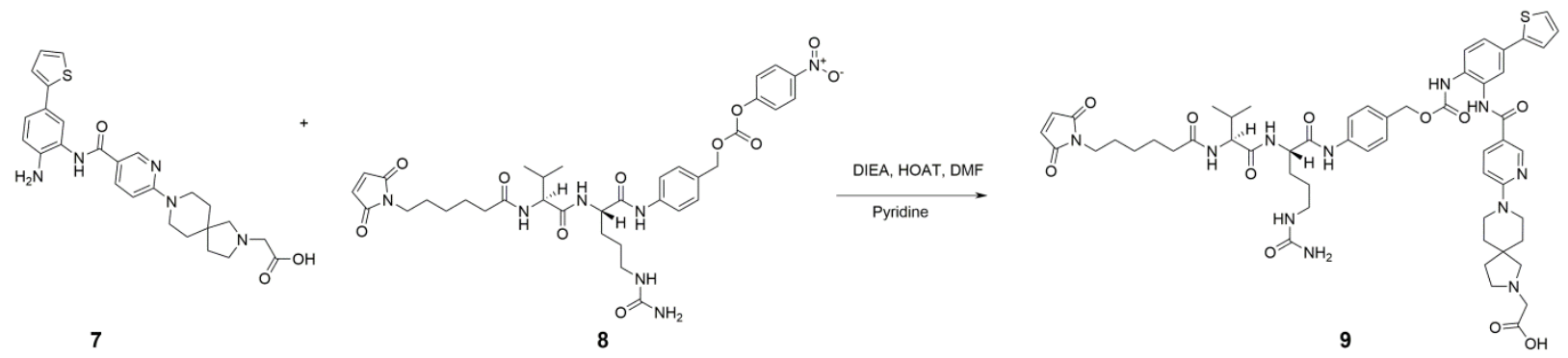

mc-Val-Cit-PABC-Spirocyclic Nicotinamide (9). The spirocyclic nicotinamide intermediate 7 (0.27 g, $0.55 \mathrm{mmol}$ ) was combined with HOAT (0.20 g, $1 \mathrm{mmol})$, DIEA, (0.02 g, $0.1 \mathrm{mmol}$ ), and pyridine $(0.02 \mathrm{~g}, 0.1 \mathrm{mmol})$ in a vial, diluted with $3.0 \mathrm{~mL}$ of dry DMA (sure seal bottle) and treated with the nitro carbonate compound 8 (1.0 g, $1.4 \mathrm{mmol})$. The vial was capped and the resultant reaction solution was stirred at $50^{\circ} \mathrm{C}$ for $2 \mathrm{~h}$. The reaction solution was then cooled to ambient temperature and triturated with $\operatorname{MTBE}(3 \times 15 \mathrm{~mL})$. The residue recovered was purified first by normal phase chromatography on a 24 gram column eluting with $0-100 \% \mathrm{MeOH}$ in DCM. The material recovered was then further purified by reverse phase chromatography on a Sunfire C18 4.6 x 50 mm $5 \mu$ m column eluting with acetonitrile/water each containing 0.05\% TFA. The desired material 9 was recovered as a white solid (0.2 g, 33\% yield). LRMS (ESI) $\mathrm{m} / \mathrm{z} 1090.6(\mathrm{M}+\mathrm{H}), 545.9(1 / 2 \mathrm{M}+) ;{ }^{1} \mathrm{H}$ NMR (600 MHz, 1/1 CD $\left.3 \mathrm{OD} / \mathrm{DMSO}-d_{6}\right) \delta 9.74(\mathrm{~s}$, 1H), 8.66 (br. s., $1 \mathrm{H}$ ), 8.15 (d, $J=7.63 \mathrm{~Hz}, 1 \mathrm{H}$ ), 8.01 (dd, $J=8.80,1.76 \mathrm{~Hz}, 1 \mathrm{H}$ ), 7.87 (s, $1 \mathrm{H}$ ), $7.56(\mathrm{~d}, J=8.22 \mathrm{~Hz}, 2 \mathrm{H}), 7.48-7.53(\mathrm{~m}, 2 \mathrm{H}), 7.36-7.40(\mathrm{~m}, 2 \mathrm{H}), 7.33(\mathrm{~d}, J=8.22 \mathrm{~Hz}, 2 \mathrm{H})$, $7.06-7.11(\mathrm{~m}, 1 \mathrm{H}), 6.91(\mathrm{~d}, J=9.39 \mathrm{~Hz}, 1 \mathrm{H}), 6.76(\mathrm{~s}, 2 \mathrm{H}), 5.16(\mathrm{~s}, 2 \mathrm{H}), 4.48-4.56(\mathrm{~m}, 1 \mathrm{H})$, 4.23 (s, 2H), 4.12 (d, $J=7.63 \mathrm{~Hz}, 1 \mathrm{H}), 3.79-3.85(\mathrm{~m}, 3 \mathrm{H}), 3.66-3.74(\mathrm{~m}, 3 \mathrm{H}), 3.45(\mathrm{t}, J=$ $7.04 \mathrm{~Hz}, 2 \mathrm{H}), 3.17-3.26(\mathrm{~m}, 2 \mathrm{H}), 3.06-3.14(\mathrm{~m}, 2 \mathrm{H}), 2.28(\mathrm{t}, J=7.34 \mathrm{~Hz}, 2 \mathrm{H}), 2.11-2.17$ (br.s., 2H), $2.04-2.11$ (m, 2H), $1.87-1.95$ (m, 2H), $1.71-1.85$ (m, 6H), $1.51-1.67$ (m, 7H), $1.26-1.34$ (m, 3H), 0.98 (d, $J=5.28 \mathrm{~Hz}, 6 \mathrm{H})$. 
Supplemental Figure S1. Relative activity of liver preparations as assessed by cleavage of the probe substrate Z-RR-AMC at pH 5.0. (A) Rat liver CLF at two protein concentrations; (B) Human liver S9 fraction at two concentrations; (C) Rat liver CLF, human liver S9 fraction, and N87 CLF, normalized for protein content.
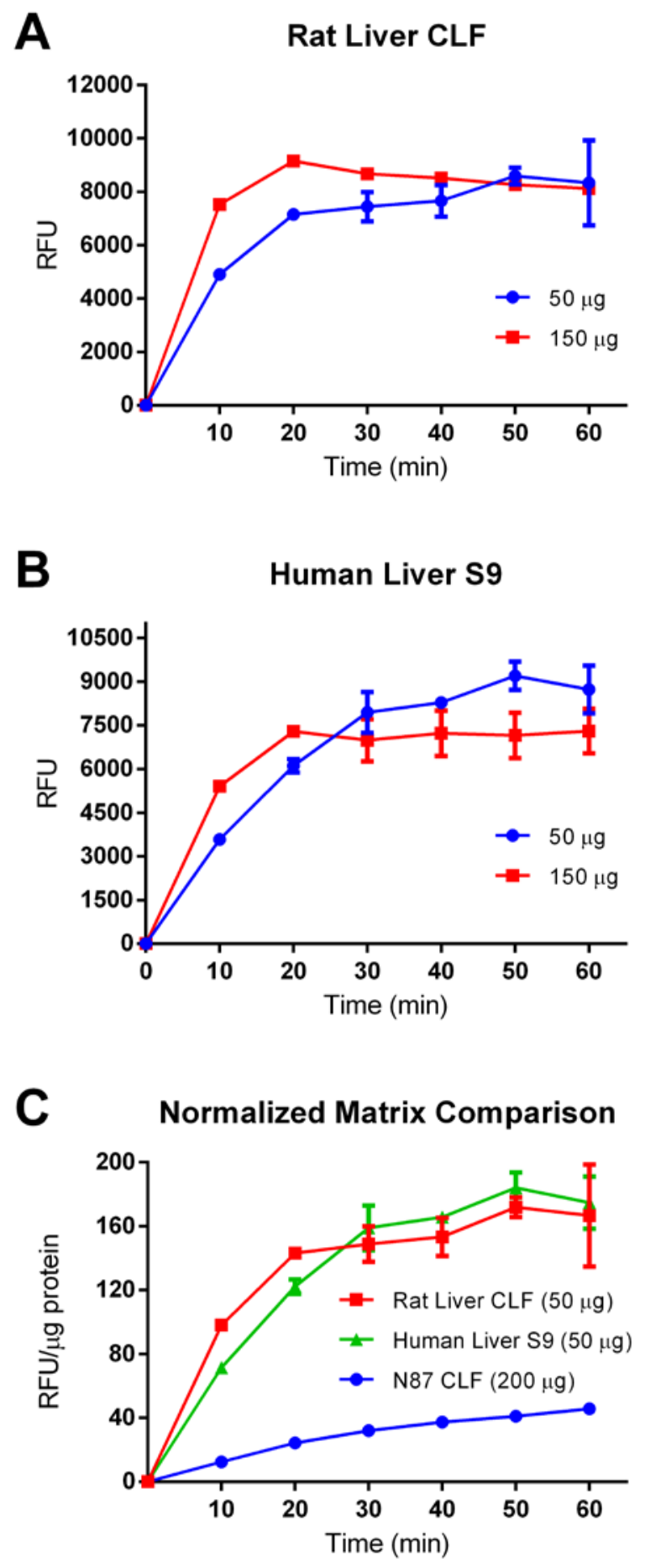
Supplemental Figure S2. The release of the spirocyclic nicotinamide payload from cysteineconjugated ADC III containing the mc-vc-PABC cleavable linker. By $18 \mathrm{~h}$, the release of the spirocyclic nicotinamide product $(\mathrm{m} / \mathrm{z}$ 492.206) was observed in incubations with purified cathepsin B, mouse liver CLF, and human liver S9 fraction. The expected product was monitored by targeted $\mathrm{MS}^{2}$ of $\mathrm{m} / \mathrm{z}$ 492.21, and no other products were observed by examination of the full scan MS data.

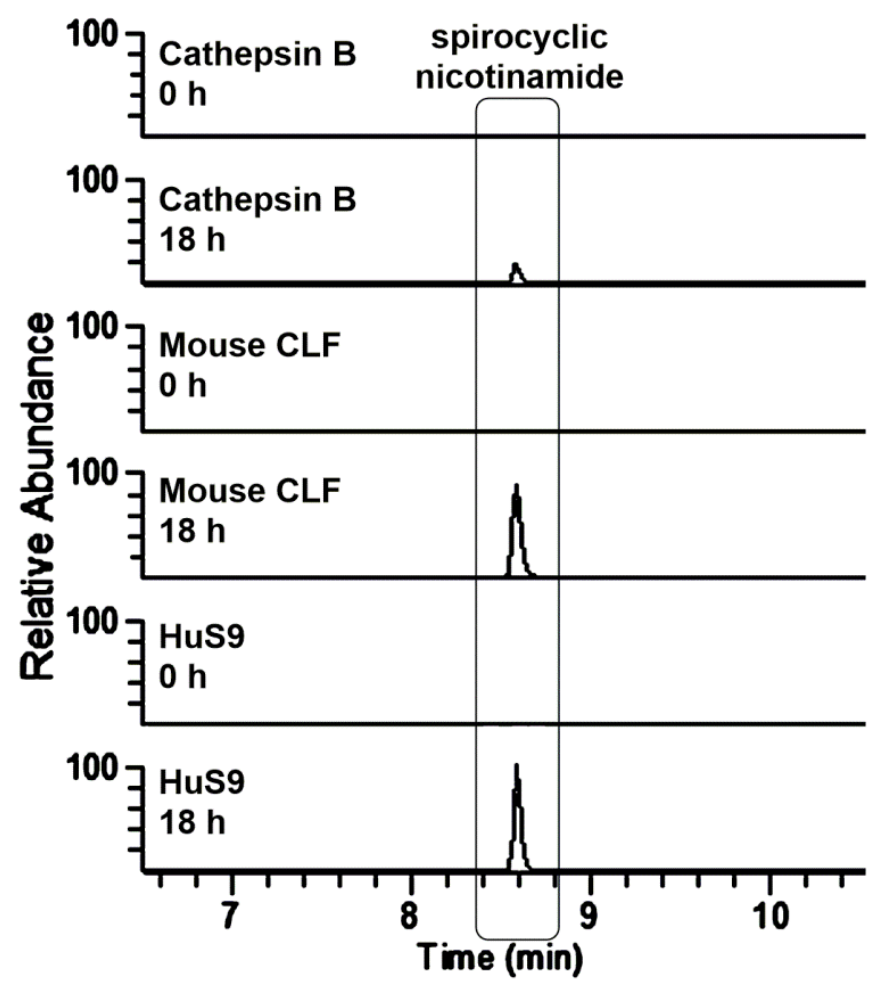


Supplemental Figure S3. CID spectrum of Cys-mc-MMAF, the product of lysosomal release from noncleavable ADC II. The intense payload fragment ion at $\mathrm{m} / \mathrm{z} 619.41$ can be observed.
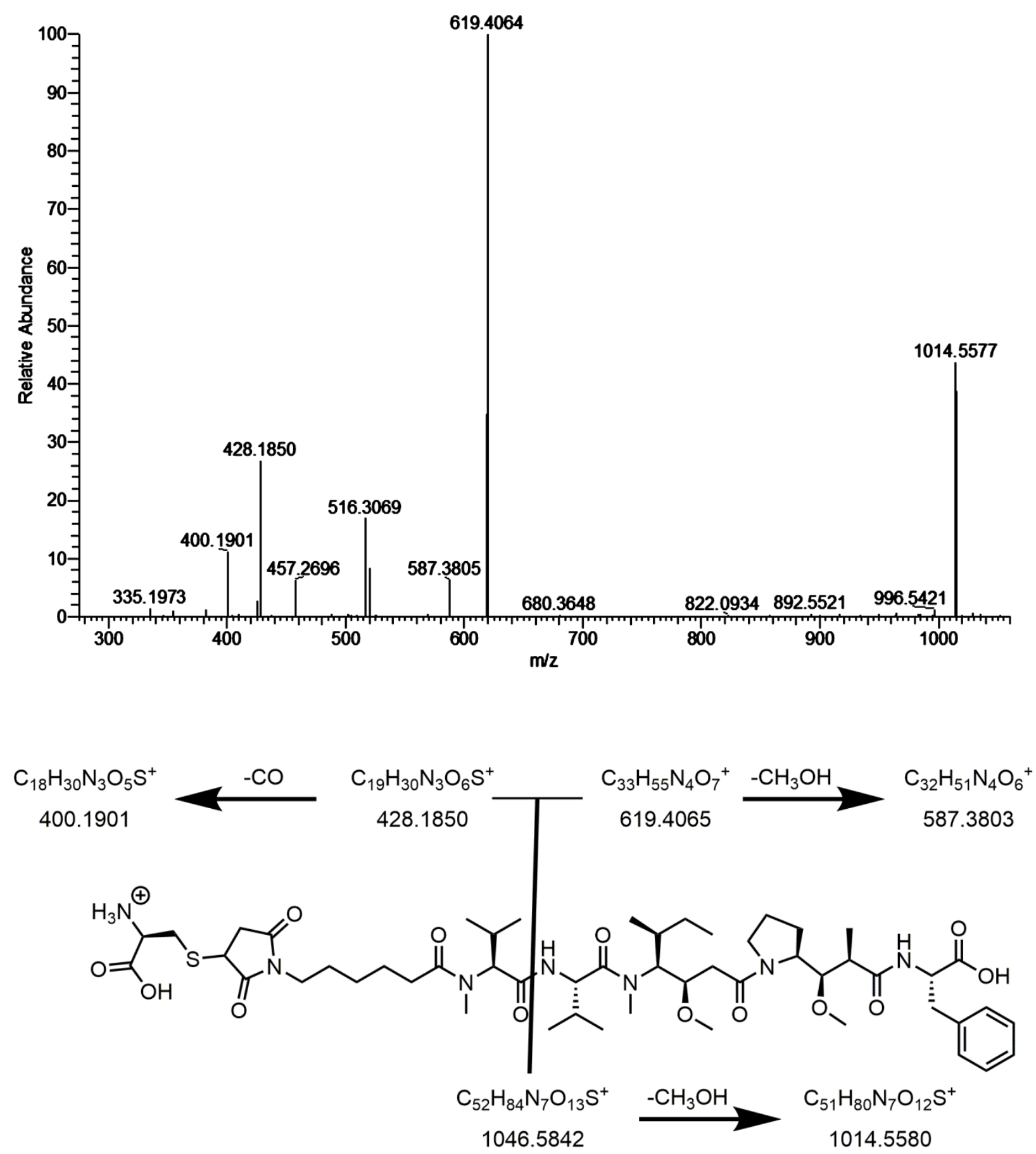
Supplemental Figure S4. Mass chromatograms of noncleavable cysteine ADC II after $0 \mathrm{hr}$ (blue trace) and $24 \mathrm{~h}$ (red trace) of incubation time with mouse liver CLF. The heavy chain peaks are highly digested by $24 \mathrm{~h}$, but the light chain peaks are largely unchanged (top). The XIC of $m / z 619.41$ (middle pane) shows peaks which contain the MMAF payload, and compares well with radiochromatograms (bottom pane) from incubations with $\left[{ }^{3} \mathbf{H}\right]$ ADC II.

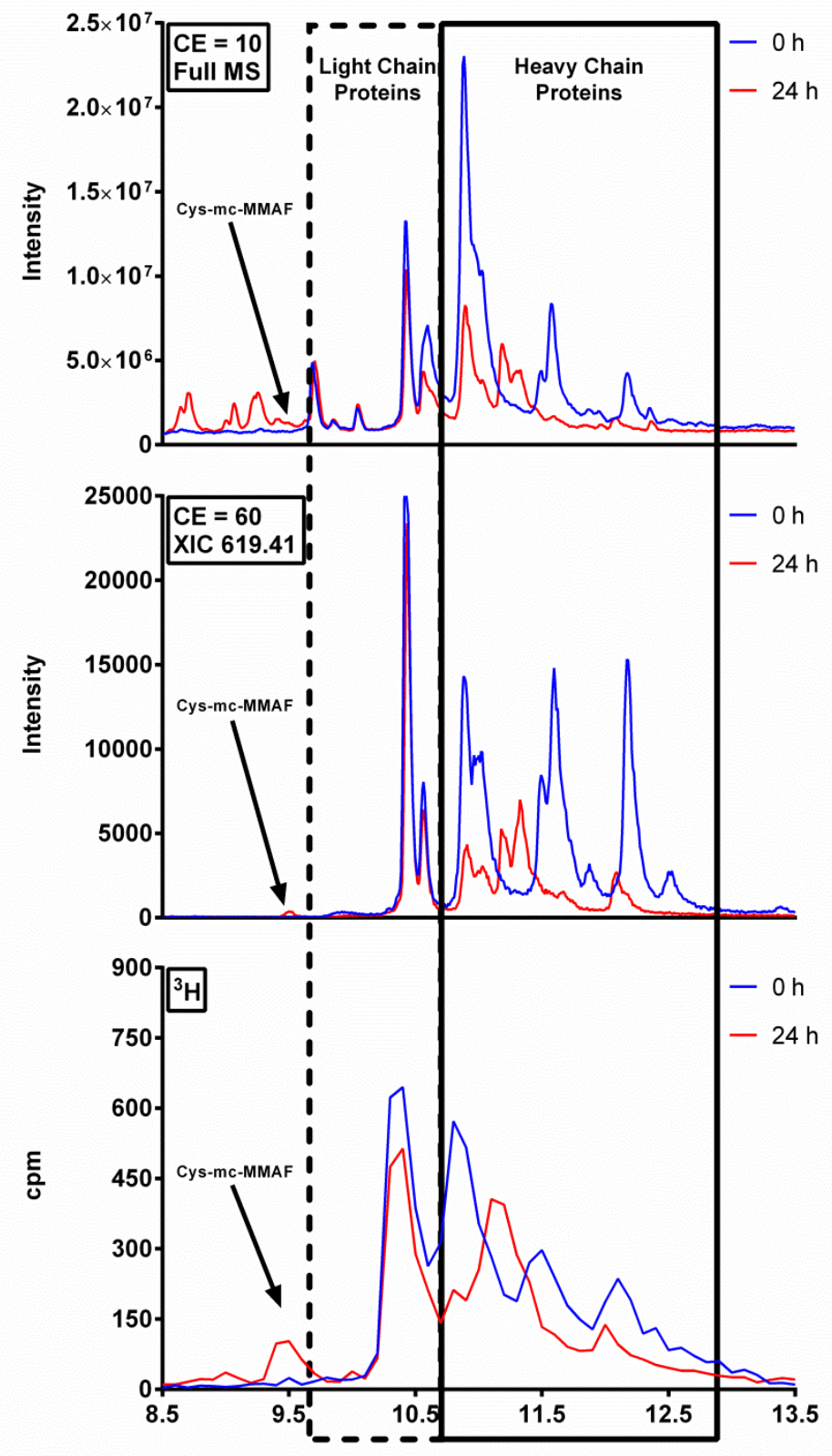


Supplemental Figure S5. CID spectrum of the spirocyclic nicotinamide payload product of lysosomal release from ADC III. The intense fragment ion at $\mathrm{m} / \mathrm{z} 302.15$ can be observed.
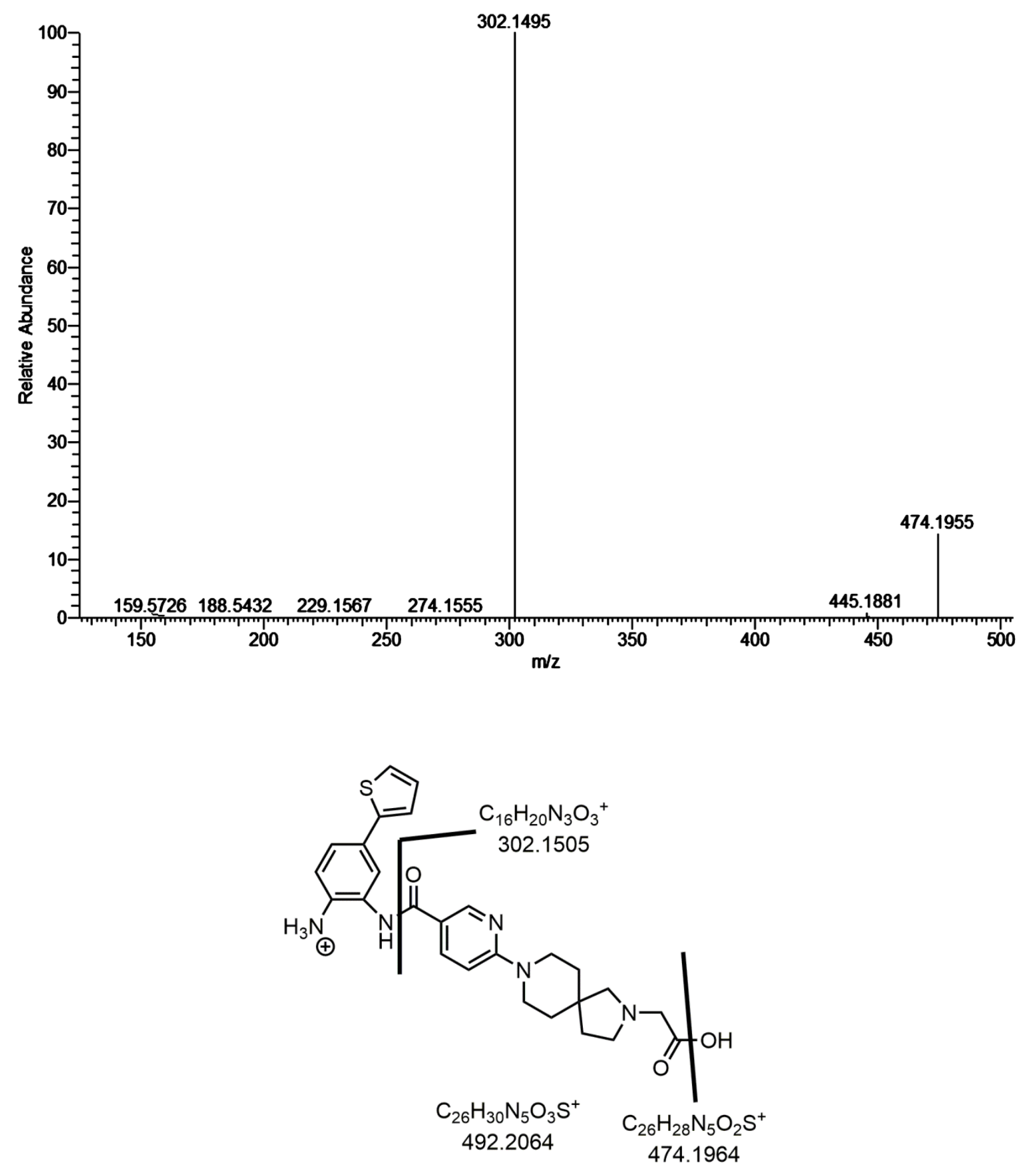